DR OMAR KUJAN (Orcid ID : 0000-0002-5951-8280)

Article type : Special Issue Article

\title{
The Role of Cyclin-Dependent Kinases in Oral Potentially Malignant Disorders and Oral Squamous Cell Carcinoma
}

Omar Kujan $^{1 *}$, Gareth Huang ${ }^{1}$, Ashwati Ravindran ${ }^{1}$, Monisha Vijayan ${ }^{1}$, Camile S. Farah ${ }^{1,2}$

${ }^{1}$ UWA Dental School, The University of Western Australia, Nedlands, WA 6009, Australia;

${ }^{2}$ Australian Centre for Oral Oncology Research \& Education, Nedlands, WA 6009, Australia

\section{*Corresponding author:}

Dr Omar Kujan

UWA Dental School

17 Monash Avenue, Nedlands WA 6009, Australia

Email: omar.kujan@uwa.edu.au

Key words: Oral cancer, cyclin-dependent kinases, oral squamous cell carcinoma, oral potentially malignant disorders, biomarkers

Running title: Cyclin-dependent kinases in oral cancer

Camile S Farah: ORCID: 0000-0002-1642-6204

\begin{abstract}
Oral squamous cell carcinoma (OSCC) is a major global health problem with a relatively low-moderate 5-year survival rate. OSCC is often preceded by lesions and conditions known as oral potentially malignant disorders (OPMD) that have an increased risk of malignant This article has been accepted for publication and undergone full peer review but has not been through the copyediting, typesetting, pagination and proofreading process, which may lead to differences between this version and the Version of Record. Please cite this article as doi: 10.1111/jop.12903

This article is protected by copyright. All rights reserved.
\end{abstract}


transformation. Despite advances in diagnostic technology and cancer research, the prognosis of OSCC remains poor as it is frequently detected a late stage. Understanding the molecular pathways involved in oral carcinogenesis provides a platform to identify biomarkers that may allow the early detection of OSCC and accurate prediction of the malignant potential of OPMDs. In addition, specific molecular inhibitors can be developed to target these important pathways and allow advanced therapeutic management to improve the prognosis of this malignancy. A common feature across a number of different cancers is the dysfunction of cell cycle moderator proteins known as cyclin-dependent kinases. This review summarises the current literature regarding the role of cyclin-dependent kinases in oral carcinogenesis with a particular focus on cyclin-dependent kinases 4 (CDK4) and 6 (CDK6). This is of particular relevance as CDK4 and CDK6 inhibitors have shown some promising results in other cancer types, and are interesting potential treatments for OSCC.

\section{Introduction}

Oral cancer presents a significant disease burden. In 2018, there were 354,864 new cases of lip and oral cavity cancer globally, with 177,384 deaths. ${ }^{1}$ Oceania has the highest agestandardised rate (ASR) incidence for both sexes of 7.4/100,000 per person, while the global ASR incidence is reportedly 4.0/100,000 per person. ${ }^{2}$ In Australia, the number of newly diagnosed lip, oral cavity and oropharyngeal cancers has increased from 1,263 to 2,037 cases during the period from 1982 to $2013 .^{3}$

Approximately $90 \%$ of malignant tumours of the oral cavity and oropharynx are oral squamous cell carcinoma (OSCC), arising either de novo or developing from oral potentially malignant disorders (OPMDs). ${ }^{4,5}$ The latter is more commonly seen, with a worldwide prevalence of $4.47 \%(95 \% \mathrm{CI}=2.43-7.08) .{ }^{6}$ Despite the improvement in knowledge pertaining to OSCC as well as advances in diagnostic approaches and multidisciplinary treatment, the 
relative 5-year survival rate of OSCC remains at approximately $50 \% .{ }^{4}$ Delayed detection and diagnosis has been postulated as one of the main reasons for the poor prognosis of OSCCs. ${ }^{4}$ The identification of reliable biomarkers, especially those detectable in OPMDs and early OSCCs, may serve as a method to develop targeted molecular-based therapy for the early diagnosis and management of OSCCs. ${ }^{7}$

OPMDs are oral lesions and conditions that have an increased risk of malignant transformation to OSCC. ${ }^{8}$ The persistence of OPMDs have the ability to cause additional complexity when detecting and diagnosing OSCCs. Currently, both clinical features and histopathological evidence of epithelial dysplasia are used to assess the potential for malignant transformation of OPMDs. ${ }^{7,8}$ Generally, the use of these indicators combined with other modalities for monitoring mucosal lesions, are able to identify high-risk lesions before they transform into malignancy. However, due to variations and inconsistencies, the detection and diagnosis of OSCC can either be missed or delayed, causing issues with further surveillance and subsequent treatment. Therefore, a more definitive means of detection with the use of reliable biomarkers is paramount for the early and effective detection of OSCCs and OPMDs. ${ }^{7}$

The development of OSCCs can be attributed to a number of risk factors including tobacco use, alcohol consumption, poor or deficient diet, betel nut chewing practices, immunodeficiencies, excessive ultraviolet radiation exposure for lip cancers and human papillomavirus infection specifically for oropharyngeal tumours. ${ }^{9-11}$ Mutation of regulatory tumour suppressor genes (TSGs) and proto-oncogenes is responsible for carcinogenesis due to their vital role in regulating the cell cycle. ${ }^{5}$ Proto-oncogenes encode for growth factors and their receptors, transcription factors, cyclins and cyclin-dependent kinases (CDKs). When 
mutation of the proto-oncogene DNA segment leads to the aberrant proliferation of cyclins or CDKs, disruption in the regulation of the cell cycle occurs, contributing to the progression of OSCC. $^{12}$

Of the CDKs, CDK4 and CDK6 in particular have been widely researched for their role in breast cancer. ${ }^{13}$ It has been found that the cyclin D1-CDK4/6 complex is dysregulated in the early stages of breast carcinogenesis where cyclin D1 is often found to be overexpressed. ${ }^{14}$ It has also been found that the complex is important for the maintenance and progression of breast cancer. ${ }^{15}$ In light of the therapeutic potential of CDK4 and CDK6 in breast cancer, its applicability to oral cancer has recently been of considerable interest. As there is currently only sparse evidence available in the literature about the role of CDK4 and CDK6 in oral cancer, further research into this area is required to drive the development of potential therapeutics.

\section{CDKs and oral carcinogenesis}

In the carcinogenesis process, the dysregulation of cell-cycle control is a substantial prerequisite. ${ }^{16}$ Hanahan and Weinberg stated eight features of cancers known as the hallmarks of cancer. ${ }^{17}$ Current knowledge strongly supports that CDK dysregulation is implicated in several hallmarks of cancer such as sustaining proliferative signalling, ${ }^{18}$ resisting cell death, ${ }^{16}$ inducing angiogenesis, ${ }^{19}$ activating invasion and metastasis, ${ }^{20}$ and energy metabolism. ${ }^{21}$

This article is protected by copyright. All rights reserved. 
CDKs are a family of protein kinases with multiple functions, one of which is to regulate the cell cycle (Figure 1). ${ }^{22}$ Specifically, they act as checkpoints and drivers for the smooth transition from one phase to the next. Two groups of CDKs have been identified - those that regulate progression of the cell cycle (CDK1-4, CDK6), and those that regulate gene transcription via RNA polymerase II (RNAPII; CDK7-9, CDK12). The function of each CDK is unique, yet they serve a similar overall purpose, which is to ensure that the progression of the cell cycle is orderly and results in normal cells. CDK activity can be inhibited by cyclin-dependent kinase inhibitors (CDKIs) and activated by the formation of protein complexes with specific cyclins which allows modulation of their functions. ${ }^{23}$

It is also worthy to remember that cyclin and CDKs work together to control the cell cycle, and neither CDKs nor cyclin work alone. ${ }^{23}$ Therefore, CDKs bind to cyclin to form a cyclinCDK complex where cyclin acts as a regulator, and CDKs act as a catalyst. ${ }^{23}$ Interestingly, in each stage of the cell cycle, there is a specific cyclin-CDK complex responsible for the regulation of the associated stage. Overall, the progression of the cell cycle is controlled by sequential activation and inactivation of cyclin-CDK complexes. ${ }^{23}$

The role of CDKs in oral carcinogenesis has attracted researcher interest for many years. Several studies reveal an alteration of the expression of CDKs in oral squamous cell carcinoma (OSCC). ${ }^{24-27}$ In this regard, Ansari et al. analysed the TCGA database in order to identify the level of dysregulation of cell cycle genes among 24 different human cancers and the impact of these genes on patient survival. Interestingly, head and neck squamous cell carcinoma was ranked among the top four cancers by means of deregulated cell cycle genes. Moreover, the median gene expression of all CDKs (mainly CDK4 and CDK6) was greater than the global gene expression, supporting a significant role of CDKs in oral carcinogenesis. $^{28}$ 
The first group of CDKs (CDK1-4, CDK6) control progression from one stage of the cell cycle to the next. CDK1 binds with cyclin $\mathrm{B} 1$, which results in the progression from $\mathrm{G} 2$ to $\mathrm{M}$ phases. It also maintains pluripotency and genomic stability in stem cells. Down-regulation of CDK1 results in loss of pluripotency and its overexpression has been correlated with ovarian cancer and OSCC. ${ }^{2,29-31} \mathrm{CDK} 2$ binds to cyclin $\mathrm{E}$, resulting in the progression from late-G1 to $\mathrm{S}$ phases. CDK2 expression is amplified in OSCC, which enhances $\mathrm{pRB}$ phosphorylation and results in rapid and uncontrolled entry into the $S$ phase of the cell cycle. ${ }^{23}$ CDK4 and CDK6 bind with cyclin D1 which results in the progression from G1 to $\mathrm{S}$ phases. This is mediated by the hyperphosphorylation of the CDK4/CDK6/cyclinD1 complex, which inactivates retinoblastoma protein $(\mathrm{pRb})$ and releases the transcription factor $\mathrm{E} 2 \mathrm{~F}$ which permits entry into the S phase. ${ }^{14}$ There is evidence that both CDK4 and CDK6 are overexpressed in OSCC, suggesting that these enzymes may play a role in the development of OSCC. Overexpression of CDK4 was evident in dysplastic oral leukoplakia as well as OSCC, suggesting that CDK4 may be an early signal of OSCC development. ${ }^{32,33}$ In contrast, CDK6 expression was correlated with a more advanced tumour state..$^{32,33}$

Interestingly, Mihara et al. revealed that CDK2 expression was significantly correlated with lymph node metastasis, tumour differentiation, mode of tumour invasion, and a shorter survival period. ${ }^{34}$ Likewise, Chen et al. showed that CDK1 expression was significantly correlated with recurrent tumours and lymph node metastasis. Therefore, CDK1 was considered a poor prognostic indicator among patients with OSCC. ${ }^{25}$ Furthermore, Poomsawat et al. documented that CDK4 and CDK6 were overexpressed in OSCC compared to normal tissue. ${ }^{27}$ Similarly, Ansari et al. revealed that overexpression of CDK6 is significantly correlated with a reduction in patient survival. ${ }^{28}$ 
The second group of CDKs (CDK7-9, CDK12) regulate gene transcription by acting on RNAPII. CDK7 has an important role in controlling mRNA synthesis (via pre-initiation complexes) and overall gene expression, thus determining cell cycle progression. ${ }^{35}$ It is involved in transcription initiation via the phosphorylation of RNAPII, which initiates an activation cascade of CDKs involved in transcription. ${ }^{36}$ An increased expression of CDK7 is seen in invasive human cutaneous squamous cell carcinoma cases. ${ }^{36}$ However, its expression in OSCC, specifically, has not yet been elucidated. CDK8 combines with three other proteins (cyclin C, Med12 and Med13) to form a "CDK8 subcomplex" that acts to negatively regulate transcription. This permits fine-tuning of the transcription process. ${ }^{37}$ CDK 8 has been observed to be overexpressed in many types of cancers, mostly of gastrointestinal origin. ${ }^{2}$ Its over-expression is also evident in human laryngeal SCC and is related to advanced stages of the cancer. ${ }^{38,39}$ CDK9 forms a complex with cyclin $\mathrm{T}$ and cyclin $\mathrm{K}$ in order to promote transcription elongation by phosphorylating RNAPII. ${ }^{40}$ Mutations in CDK9 increases its production and consequently increases anti-apoptotic protein expression, leading to the onset of cancer. ${ }^{40}$ Its over-expression is mostly linked to lymphoma and chronic lymphocytic leukaemia. ${ }^{40}$ The expression patterns of CDK9 in OSCC have yet to be reported. CDK12 has roles in the DNA damage response as well as in cellular and developmental differentiation, however the exact mechanism by which CDK12 acts in the transcriptional regulation of these genes is not yet fully understood. Over-expression of CDK12 has been demonstrated in breast and ovarian carcinogenesis, but has not yet been investigated in OSCC. ${ }^{41}$

Over-expression of CDKs, in particular CDK4 and CDK6, has been shown to contribute to cell-cycle dysfunction in a range of cancer types. Currently, there is minimal evidence regarding the role of CDKs in the development and progression of OSCC, however we suggest that it is a promising area of investigation.

This article is protected by copyright. All rights reserved. 


\section{Expression of CDKs in OPMDs}

As the expression and role of CDKs in OSCC has been demonstrated, it is reasonable to assume that $\mathrm{CDK}$ expression plays a role in OPMD formation or development. To date, there are a limited number of studies that have explored the relationship between CDKs and OPMDs and these have primarily focussed on the expression of CDK4 and CDK6. Overall, the literature tends to postulate a gradual increase in CDK4 expression with increasing grades of dysplasia, suggesting that CDK4 is a catalyst in early oral carcinogenesis. Studies by Miliani de Marval et al. ${ }^{42}$ and Niwa et al. ${ }^{43}$ have demonstrated that exposure of carcinogens such as 4-nitroquinoline 1-oxide and 7,12-dimethybenzanthracene (DMBA) in rats and transgenic mice resulted in the over-expression of CDK4 in pre-malignant lesions. ${ }^{42,43}$ Similarly, the gradual increase in the expression of CDK4 through tissue samples ranging from hyperkeratosis, oral epithelial dysplasia (mild, moderate, and severe), and OSCC has been demonstrated by Chen et al. ${ }^{44}$ Furthermore, this evidence has been consolidated by a study conducted by Shyam et al. whereby an immunohistochemical assay was conducted in samples of normal tissue, OPMDs (leukoplakia samples) and OSCC and a gradual increase in expression of CDK4 was found with increasing grades of dysplasia. ${ }^{45}$

CDK6 tends to be expressed in established OSCC in contrast to CDK4 which is a key marker in the early transformation from epithelial dysplasia to OSCC. This concept was explored by Poomsawat et al., when they showed that CDK4 was over-expressed in oral leukoplakia with mild dysplasia and OSCC compared to normal mucosa. ${ }^{33}$ CDK6 however was only overexpressed in OSCC, with no difference in expression between oral leukoplakia with or without dysplasia and normal mucosa. ${ }^{33}$

This article is protected by copyright. All rights reserved. 
Overall, CDK4 seems to be over-expressed in OPMD and OSCC, but CDK6 is found in established OSCCs. Despite these findings, there seems to be insufficient evidence to deduce prognosis and clinical outcomes from the expression of CDKs in OPMDs.

\section{Significance and therapeutic potential of CDKs in OSCC and OPMD}

There is potential for CDKs to be used as molecular biomarkers to detect malignant transformation of OPMDs in addition to OSCCs. Several studies have elucidated the use of CDK4 and CDK6 in particular as potential biomarkers and targets for cancer therapy. Table 1 illustrates the current published studies that have examined CDK4 or CDK6 expression in specimens of OSCCs and OPMDs. With surveillance of these biomarkers, there is an opportunity to track the changes that OPMDs undergo and potentially diagnose OSCCs at an earlier and less advanced stage, and henceforth improve patients' chances of survival. There is also potential for CDKs to be used as therapeutic targets in cancer treatment. ${ }^{46}$ Inhibiting specific CDKs seems to be the key; there are pan-CDK inhibitors and newer selective CDK inhibitors (CDK4/6-selective drugs) that utilise specific miRNAs currently under investigation. At present, there are three CDK4/6 inhibitors tested in clinical trials palbociclib, ribociclib and abemaciclib. The effects of these drugs have been studied extensively in breast cancer and display promising clinical outcomes. ${ }^{13}$ Interestingly, the efficacy and safety of the CDK4/6 inhibitor ribociclib combined with letrozole for first-line treatment in women with hormone receptor-positive/HER2-negative recurrent or metastatic breast cancer has been studied and their results were very encouraging. ${ }^{47}$ Further research is required to ascertain whether the same concept of CDK4/6 inhibitor drugs can be applied in

OSCC patients in light of various studies showing the importance of CDK4/6 overexpression in OSCC.

This article is protected by copyright. All rights reserved. 


\section{Conclusions}

Dysfunction in normal cell cycle processes and aberrant turnover of cells are key contributors to cancer development. With this notion, cell cycle moderator enzymes or CDKs have been investigated for their role in carcinogenesis with a particular focus on the expression levels of CDK4 and CDK6. However, there is a limited amount of evidence available that quantitatively demonstrates expression levels of these biomarkers in OPMDs and OSCCs. Hence, with further research and a greater understanding of the role of CDKs in oral carcinogenesis, there is the possibility of using particular CDKs not only as biomarkers for early detection of OPMDs and OSCCs, but also as potential therapeutic targets in order to actively treat and control cancer progression and ultimately reduce morbidity and mortality rates. 
Table 1: Studies which have examined CDK4 or CDK6 expression in OSCCs and OPMDs

\begin{tabular}{|c|c|c|c|c|c|c|}
\hline No. & Authors, Year & $\begin{array}{l}\text { Type of } \\
\text { Study }\end{array}$ & $\begin{array}{l}\text { Type and Number } \\
\text { of Samples }\end{array}$ & Biomarkers Tested & $\begin{array}{l}\text { Methods of Detection } \\
\text { of CDKs }\end{array}$ & Results \\
\hline 1 & $\begin{array}{l}\text { Chen et al., } \\
1999^{44}\end{array}$ & Retrospective & $\begin{array}{l}15 \text { OSCC } \\
30 \text { OPMD }\end{array}$ & $\begin{array}{l}\text { CDK4 } \\
\text { p16 }\end{array}$ & Immunohistochemistry & $\begin{array}{l}\text { Overexpression of CDK4 in } \\
\text { OSCC } \\
\text { Progressive overexpression } \\
\text { of CDK } 4 \text { in increasing } \\
\text { grades of dysplasia }\end{array}$ \\
\hline 3 & $\begin{array}{l}\text { Niwa et al., } \\
2001^{43}\end{array}$ & Prospective & $\begin{array}{l}50 \text { rats exposed to } \\
\text { carcinogens (tongue } \\
\& \text { oral mucosa) } \\
10 \text { rats unexposed } \\
\text { to carcinogens }\end{array}$ & $\begin{array}{l}\text { CDK4 } \\
\text { pRb } \\
\text { cyclin D1 } \\
\text { PCNA }\end{array}$ & $\begin{array}{l}\text { Immunohistochemistry } \\
\text { Western blotting }\end{array}$ & $\begin{array}{l}\text { Gradual overexpression of } \\
\text { CDK4 in premalignant } \\
\text { lesions }\end{array}$ \\
\hline 5 & $\begin{array}{l}\text { Poomsawat et al., } \\
2010^{33}\end{array}$ & Retrospective & $\begin{array}{l}15 \text { OSCC } \\
14 \text { oral leukoplakia } \\
\text { with dysplasia } \\
20 \text { oral leukoplakia } \\
\text { without dysplasia }\end{array}$ & $\begin{array}{l}\text { CDK4 } \\
\text { CDK6 }\end{array}$ & Immunohistochemistry & $\begin{array}{l}\text { Overexpression of CDK4 } \\
\text { and CDK6 in OSCC } \\
\text { Overexpression of CDK4 in } \\
\text { oral leukoplakia with } \\
\text { dysplasia }\end{array}$ \\
\hline
\end{tabular}

This article is protected by copyright. All rights reserved. 


\begin{tabular}{|c|c|c|c|c|c|c|}
\hline & & & 12 normal mucosa & & & \\
\hline 7 & $\begin{array}{l}\text { Shyam et al., } \\
2014^{45}\end{array}$ & Retrospective & $\begin{array}{l}30 \text { OSCC } \\
15 \text { oral leukoplakia } \\
17 \text { normal oral } \\
\text { tissue }\end{array}$ & CDK4 & Immunohistochemistry & $\begin{array}{l}\text { Progressive overexpression } \\
\text { of CDK4 in increasing } \\
\text { grades of dysplasia } \\
\text { Progressive overexpression } \\
\text { of CDK4 from poorly } \\
\text { differentiated to well } \\
\text { differentiated OSCC }\end{array}$ \\
\hline
\end{tabular}

This article is protected by copyright. All rights reserved. 
Figure 1: Cyclin and CDK function in the cell cycle. Adapted from: Luftul et al (2016) ${ }^{22}$

References

1. Bray F, Ferlay J, Soerjomataram I, Siegel RL, Torre LA, Jemal A. Global cancer statistics 2018: GLOBOCAN estimates of incidence and mortality worldwide for 36 cancers in 185 countries. CA Cancer J Clin. 2018;68(6):394-424.

2. Peyressatre $M$, Prevel $C$, Pellerano $M$, Morris MC. Targeting cyclin-dependent kinases in human cancers: from small molecules to Peptide inhibitors. Cancers (Basel). 2015;7(1):179-237.

3. Pollaers K, Kujan O, Johnson NW, Farah CS. Oral and oropharyngeal cancer in Oceania:Incidence, mortality, trends and gaps in public databases as presented to the Global Oral Cancer Forum. Translational Research in Oral Oncology. 2017;2:2057178X17726455.

4. Scully C, Bagan J. Oral squamous cell carcinoma overview. Oral Oncol. 2009;45(45):301-308.

5. Proweller A, Tu L, Lepore JJ, et al. Impaired notch signaling promotes de novo squamous cell carcinoma formation. Cancer Res. 2006;66(15):7438-7444.

6. Mello FW, Miguel AFP, Dutra KL, et al. Prevalence of oral potentially malignant disorders: A systematic review and meta-analysis. J Oral Pathol Med. 2018;47(7):633-640.

7. Farah CS, Woo S-B, Zain RB, Sklavounou A, McCullough MJ, Lingen M. Oral cancer and oral potentially malignant disorders. Int J Dent. 2014;2014:853479.

8. Speight PM, Khurram SA, Kujan O. Oral potentially malignant disorders: risk of progression to malignancy. Oral Surg Oral Med Oral Pathol Oral Radiol. 2018;125(6):612-627.

9. Kujan O, Husain A, Farah CS. Alcohol and Oral Cancer. In: Al Moustafa A-E, ed. Development of Oral Cancer: Risk Factors and Prevention Strategies. Cham: Springer International Publishing; 2017:61-82.

10. Liao C-T, Wallace CG, Lee L-Y, et al. Clinical evidence of field cancerization in patients with oral cavity cancer in a betel quid chewing area. Oral Oncol. 2014;50(8):721-731.

11. Farah CS, Kujan O, Prime S, Zain RB. Oral Mucosal Malignancies: A Comprehensive Approach to Clinical Practice. In: Camile SF, Ramesh B, Michael J M, eds. Contemporary Oral Medicine: Springer International Publishing; 2018.

12. Croce CM. Oncogenes and cancer. N Engl J Med. 2008;358(5):502-511.

13. Vijayaraghavan S, Moulder S, Keyomarsi K, Layman RM. Inhibiting CDK in Cancer Therapy: Current Evidence and Future Directions. Target Oncol. 2018;13(1):21-38.

14. Finn RS, Aleshin A, Slamon DJ. Targeting the cyclin-dependent kinases (CDK) $4 / 6$ in estrogen receptor-positive breast cancers. Breast Cancer Res. 2016;18(1):17.

15. DiPippo AJ, Patel NK, Barnett CM. Cyclin-Dependent Kinase Inhibitors for the Treatment of Breast Cancer: Past, Present, and Future. Pharmacotherapy. 2016;36(6):652-667.

16. Lundberg AS, Weinberg RA. Control of the cell cycle and apoptosis. Eur J Cancer. Dec 1999;35(14):1886-1894.

This article is protected by copyright. All rights reserved. 
17. Hanahan D, Weinberg RA. Hallmarks of cancer: the next generation. Cell. Mar 4 2011;144(5):646-674.

18. Duronio RJ, Xiong Y. Signaling pathways that control cell proliferation. Cold Spring Harb Perspect Biol. Mar 1 2013;5(3):a008904.

19. Wei $R$, Kong $L$, Xiao $Y$, et al. CDK8 regulates the angiogenesis of pancreatic cancer cells in part via the CDK8-beta-catenin-KLF2 signal axis. Exp Cell Res. Aug 15 2018;369(2):304-315.

20. Liu T, Yu J, Deng M, et al. CDK4/6-dependent activation of DUB3 regulates cancer metastasis through SNAIL1. Nat Commun. Jan 9 2017;8:13923.

21. Solaki M, Ewald JC. Fueling the Cycle: CDKs in Carbon and Energy Metabolism. Front Cell Dev Biol. 2018;6:93.

22. Lutful Kabir FM, Alvarez CE, Bird RC. Canine Mammary Carcinomas: A Comparative Analysis of Altered Gene Expression. Vet Sci. 2015;3(1).

23. Malumbres M. Cyclin-dependent kinases. Genome Biol. 2014;15(6):122.

24. Timmermann S, Hinds PW, Munger K. Elevated activity of cyclin-dependent kinase 6 in human squamous cell carcinoma lines. Cell Growth Differ. Apr 1997;8(4):361-370.

25. Chen $\mathrm{X}$, Zhang FH, Chen QE, et al. The clinical significance of CDK1 expression in oral squamous cell carcinoma. Med Oral Patol Oral Cir Bucal. Jan 1 2015;20(1):e7-12.

26. Andisheh-Tadbir A, Ashraf MJ, Jeiroodi N. Expression of CDK6 in Oral Squamous Cell Carcinomas. Asian Pac J Cancer Prev. Apr 25 2018;19(4):1013-1016.

27. Poomsawat S, Buajeeb W, Khovidhunkit SO, Punyasingh J. Alteration in the expression of cdk4 and cdk6 proteins in oral cancer and premalignant lesions. J Oral Pathol Med. Nov 2010;39(10):793-799.

28. Ansari SS, Sharma AK, Zepp M, et al. Upregulation of cell cycle genes in head and neck cancer patients may be antagonized by erufosine's down regulation of cell cycle processes in OSCC cells. Oncotarget. Jan 19 2018;9(5):5797-5810.

29. Shi H-R, Zhang R-T. [Expression and significance of P53, P21WAF1 and CDK1 proteins in epithelial ovarian cancer]. Ai Zheng. 2009;28(8):882-885.

30. Chen $\mathrm{X}$, Zhang $\mathrm{F}-\mathrm{H}$, Chen $\mathrm{Q}-\mathrm{E}$, et al. The clinical significance of CDK1 expression in oral squamous cell carcinoma. Medicina oral, patologia oral y cirugia bucal. 2015;20(1):e7-12.

31. Mihara $M$, Shintani $S$, Nakahara $Y$, et al. Overexpression of CDK2 is a prognostic indicator of oral cancer progression. Jpn J Cancer Res. 2001;92(3):352-360.

32. Poomsawat $S$, Sanguansin $S$, Punyasingh J, Vejchapipat $P$, Punyarit $P$. Expression of cdk6 in head and neck squamous cell carcinoma. Clin Oral Investig. 2016;20(1):57-63.

33. Poomsawat S, Buajeeb W, Khovidhunkit S-o, Punyasingh J. Alteration in the expression of cdk4 and cdk6 proteins in oral cancer and premalignant lesions. J Oral Pathol Med. 2010;39(10):793-799.

34. Mihara M, Shintani S, Nakahara $Y$, et al. Overexpression of CDK2 is a prognostic indicator of oral cancer progression. Jpn J Cancer Res. Mar 2001;92(3):352-360.

35. Cao K, Shilatifard A. Inhibit globally, act locally: CDK7 inhibitors in cancer therapy. Cancer Cell. 2014;26(2):158-159.

36. Haider AS, Peters SB, Kaporis $\mathrm{H}$, et al. Genomic analysis defines a cancer-specific gene expression signature for human squamous cell carcinoma and distinguishes malignant hyperproliferation from benign hyperplasia. J Invest Dermatol. 2006;126(4):869-881.

This article is protected by copyright. All rights reserved. 
37. Knuesel MT, Meyer KD, Bernecky C, Taatjes DJ. The human CDK8 subcomplex is a molecular switch that controls Mediator coactivator function. Genes Dev. 2009;23(4):439-451.

38. Li M, Zhao X, Liu Y, An J, Xiao H, Wang C. Aberrant expression of CDK8 regulates the malignant phenotype and associated with poor prognosis in human laryngeal squamous cell carcinoma. Eur Arch Otorhinolaryngol. 2017;274(5):2205-2213.

39. Sonawane YA, Taylor MA, Napoleon JV, Rana S, Contreras JI, Natarajan A. Cyclin Dependent Kinase 9 Inhibitors for Cancer Therapy. J Med Chem. 2016;59(19):86678684.

40. Wang S, Fischer PM. Cyclin-dependent kinase 9: a key transcriptional regulator and potential drug target in oncology, virology and cardiology. Trends Pharmacol Sci. 2008;29(6):302-313.

41. Paculova $\mathrm{H}$, Kohoutek J. The emerging roles of CDK12 in tumorigenesis. Cell Div. 2017;12:7.

42. Miliani de Marval PL, Macias E, Conti CJ, Rodriguez-Puebla ML. Enhanced malignant tumorigenesis in Cdk4 transgenic mice. Oncogene. 2004;23(10):1863-1873.

43. Niwa $S$, Ueno $S$, Shirasu R. Alteration of $\mathrm{pRb}$ expression in the development of rat tongue carcinoma induced by 4-nitroquinoline 1-oxide. Oral Oncol. 2001;37(7):579585.

44. Chen Q, Luo G, Li B, Samaranayake LP. Expression of p16 and CDK4 in oral premalignant lesions and oral squamous cell carcinomas: a semi-quantitative immunohistochemical study. J Oral Pathol Med. 1999;28(4):158-164.

45. Shyam N, Rao NN, Narang RD, George J, Bommu SR, Kiran G. Immunohistochemical characterization of cyclin dependent kinase-4 in different histological grades of oral leukoplakia and oral squamous cell carcinoma. J Oral Maxillofac Pathol. 2014;18(1):36-41.

46. Asghar U, Witkiewicz AK, Turner NC, Knudsen ES. The history and future of targeting cyclin-dependent kinases in cancer therapy. Nat Rev Drug Discov. 2015;14(2):130146.

47. Hortobagyi GN, Stemmer SM, Burris HA, et al. Ribociclib as First-Line Therapy for HRPositive, Advanced Breast Cancer. N Engl J Med. 2016;375(18):1738-1748.

48. Koontongkaew S, Chareonkitkajorn L, Chanvitan A, Leelakriangsak $M$, Amornphimoltham P. Alterations of p53, pRb, cyclin D(1) and cdk4 in human oral and pharyngeal squamous cell carcinomas. Oral Oncol. 2000;36(4):334-339.

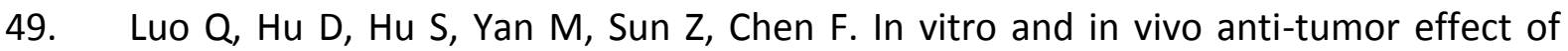
metformin as a novel therapeutic agent in human oral squamous cell carcinoma. BMC Cancer. 2012;12:517.

50. Shang $A, L u$ W-Y, Yang $M$, et al. miR-9 induces cell arrest and apoptosis of oral squamous cell carcinoma via CDK 4/6 pathway. Artif Cells Nanomed Biotechnol. 2018;46(8):1754-1762.

This article is protected by copyright. All rights reserved. 


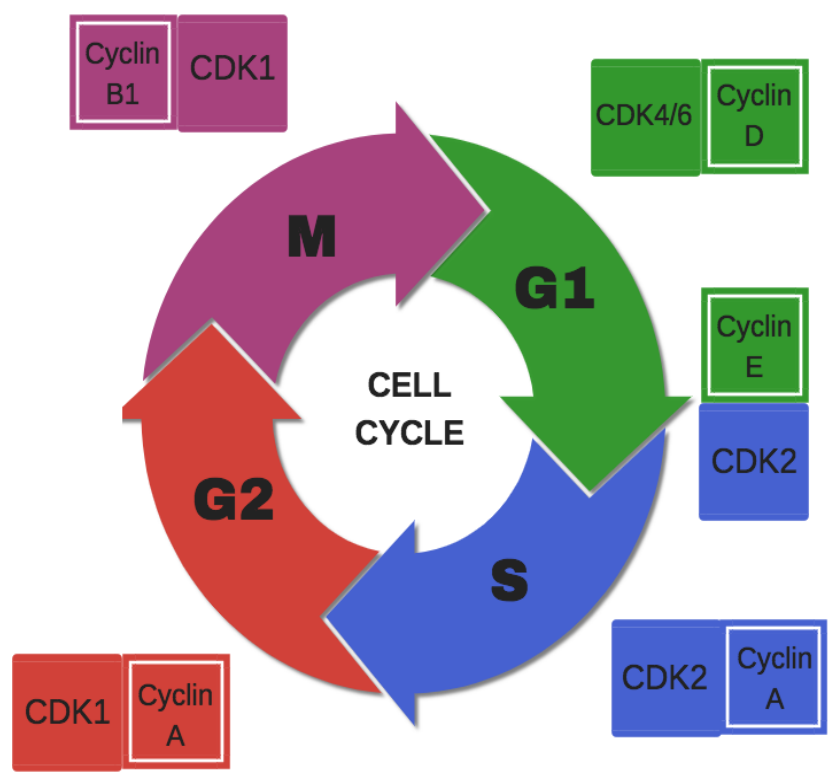

This article is protected by copyright. All rights reserved. 